\title{
Hans Paulsen
}

É com grande honra que apresento o Prof. Hans Paulsen para essa entrevista concedida durante o I Encontro de Ortodontia da Amazônia. Pesquisador de reconhecimento internacional, o Prof. Paulsen é doutor pelo Karolinska Institute em Estocolmo/Suécia e prof. visitante de diversas universidades no mundo inteiro, entre as quais a Universidade de Illinois, em Chicago/EUA e do Karolinska Institute, além de ter sido professor dos Departamentos de Ortodontia da Universidade de Aarhus e da Universidade de Copenhaguen, ambas na Dinamarca, seu país natal.

A sua experiência científica, divulgada em dezenas de artigos publicados no mundo inteiro, é centrada em temas de interesse clínico, tais como: o auto-transplante de dentes e o tratamento da Classe II com o aparelho de Herbst, os quais serão o foco maior dessa entrevista. Na área de auto-transplantes, o prof. Paulsen carrega uma experiência de mais de 25 anos, com mais de 500 casos documentados, o que o dignifica como um dos pesquisadores com maior conhecimento científico e experiência clínico-cientifica nesse assunto. O mesmo pode ser dito para o seu trabalho com o aparelho de Herbst, onde acumula uma experiência de quase 30 anos, com mais de 700 casos documentados, cujos resultados podem ser analisados nos diversos artigos publicados. Esse conhecimento o levou a fazer parte do corpo editorial dos mais importantes periódicos da Ortodontia norte-americana e européia e o tornou um dos ortodontistas europeus de maior reconhecimento mundial.

David Normando

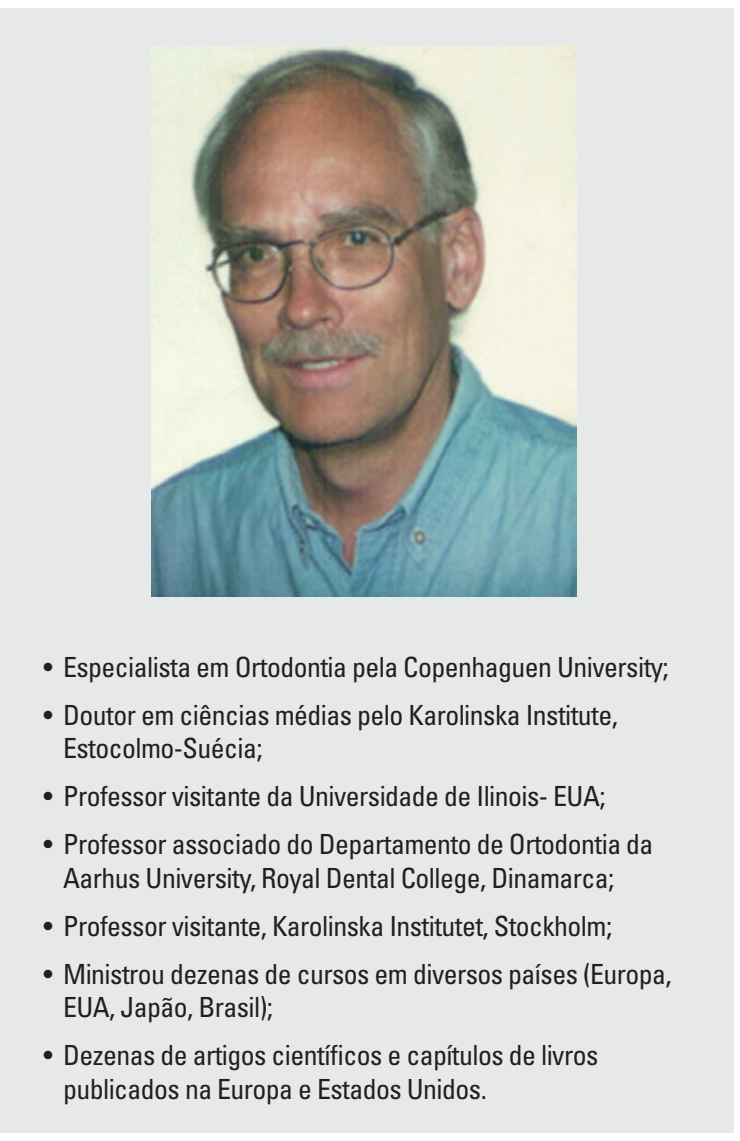

1) Na literatura recente (Angle Orthod, Appleton, v.74, no.1, p.137-44, Feb. 2004) há casos de autotransplantes com sucesso em pacientes adultos com ápices radiculares fechados. Qual sua experiência e quais as modificações da técnica para esses casos? Francisco Ajalmar Maia

$\mathrm{Eu}$ tive conhecimento desse artigo antes de ser publicado e acho muito interessante essa combinação de autotransplante com a cirurgia ortognática em casos de assimetria facial e agenesias dentárias múltiplas. O 48 foi transplantado para a região do 26, o qual fora extraído em uma jovem de 22 anos de idade. Normalmente, essa faixa etária apresentará aproximadamente $3 / 4$ de desenvolvimento radicular do 48, isto é, um molar com um ápice amplamente aberto, fácil de se remover e implantar após a criação cirúrgica de um alvéolo, aproximadamente $2 \mathrm{~mm}$ mais largo do que o diâmetro radicular do transplante. Trata-se de uma perfeita solução de tratamento, mas lembre-se: tome cuidado com todos os tecidos moles no transplante, isto é, a gengiva marginal, o ligamento periodontal, a bainha epitelial radicular de Hertwig e os tecidos pulpares. 
2) Quando uma anquilose de autotransplante funciona de forma semelhante a um implante dentário, o que se deve fazer no sentido de ser otimista com o resultado a longo prazo em um paciente jovem? Francisco Ajalmar Maia

Certamente um dente autotransplantado age de forma semelhante a um implante, visto que se torna parte do osso. Na fase inicial do diagnóstico de uma anquilose precoce, apenas poucas pontes ósseas formam-se em áreas do transplante sem o ligamento periodontal. A cirurgia pode luxar e fraturar as pontes ósseas, caso iniciada prematuramente. A rotação ortodôntica do transplante deve ser iniciada imediatamente após a cirurgia, de forma que o novo ligamento periodontal possa ser formado nas áreas de ROI e a anquilose precoce desapareça. Caso a anquilose seja detectada alguns meses depois, será impossivel romper as pontes ósseas por meio da técnica cirúrgica. Caso não haja crescimento alveolar, o dente permanecerá estável como um implante. Entretanto, em indivíduos em fase de crescimento a irrupção dentária com o crescimento alveolar vertical será considerada normal. O dente anquilosado tornar-se-á semelhante a um implante e não seguirá o trajeto normal de irrupção. Indiretamente, o transplante cada vez mais permanecerá em uma infra-posição durante o crescimento. A raiz, de certa forma, será substituída pelo osso e não se obterá um resultado com sucesso.

\section{3) Nossa experiência com o autotransplan-} te de pré-molares não tem sido satisfatória. A principal inconveniência constitui a anquilose pós-cirúrgica. Quais são as possíveis causas de tal problema? Omar Gabriel Silva Filho

Respostas possíveis: o cirurgião criou o alvéolo muito estreito, portanto o ligamento periodontal sofreu uma ruptura ao se reimplantar o transplante. A extração cirúrgica não trouxe a gengiva marginal com o dente e o ligamento periodontal total foi rompido. A cirurgia cuidadosa torna-se importante, tomando-se cuidado com os tecidos moles do transplante.
4) $O$ crescimento radicular esperado sofreu durante o transplante? Claudenir Rossato

Sim, na maioria dos casos: $14 \%$ apresentaram retração total da formação radicular, $65 \%$ retração parcial, enquanto $21 \%$ não apresentaram nenhuma retração. Os pré-molares na posição ectópica na mandíbula antes do transplante demonstraram um crescimento radicular reduzido significante comparado aos pares equiparados com a posição do enxerto dentário.

Argumentos: há a indicação de que nenhum dano, parcial ou total, na bainha radicular epitelial de Hertwig constituiu a razão para as variações no crescimento radicular.

5) Há algum benefício oclusal ou periodontal significante a longo prazo ao se substituir os incisivos laterais superiores pelo canino, em vez de se utilizar implantes, mesmo quando há uma relação molar Classe I sólida? Weber Ursi

Não sei. Temos diferenças em perspectiva ao se substituir uma morfologia lateral por uma morfologia canina - depende da morfologia dentária de um canino, caso se substitua um lateral por um canino. A alteração de uma morfologia Classe I para uma relação molar Classe II pode exigir muito tempo. Torna-se mais fácil alterar caso um lateral ausente tenha sido detectado precocemente e o tratamento tenha se iniciado relativamente cedo. Por outro lado, um lateral ausente detectado de forma tardia pode facilmente ser substituído com um implante. Também torna-se essencial avaliar a morfologia facial do paciente.

6) Qual o protocolo cirúrgico adotado no autotransplante de pré-molar na região dos incisivos centrais superiores? Weber Ursi

Depende de cada caso de tratamento, com ou sem osso, espaço e área. Deve haver $1 \mathrm{~mm}$ de espaço entre o transplante e o dente vizinho. $\mathrm{O}$ alvéolo deve ser criado $1 \mathrm{~mm}$ mais profundo e $2 \mathrm{~mm}$ mais amplo do que as dimensões radiculares do transplante. Deve haver osso alveolar ao redor do dente 
na área receptora. $\mathrm{O}$ dente deve ser posicionado em infraposição sem contato oclusal. Deve-se administrar 100 i.u. de penicilina no paciente antes da cirurgia. $\mathrm{O}$ dente deve ser fixado à gengiva marginal com uma sutura de seda durante uma semana.

\section{7) Por que os auto-transplantes não são tão populares nos Estados Unidos como na Europa? Weber Ursi}

Pode ser devido a algum mal entendido entre o ortodontista e o cirurgião. Talvez o cirurgião tenha mais experiência com implantes do que transplantes. Talvez as falhas dos transplantes tenham ocorrido pelo fato do cirurgião realizar os mesmos pré-tratamentos tanto para os implantes quanto para os transplantes. $\mathrm{O}$ pré-tratamento cirúrgico na região receptora de um implante constitui: não remover mais osso do que o necessário, visto que a formação óssea será induzida pela membrana periodontal do transplante.

\section{8) Qual a freqüência da cicatrização da pol-} pa (versus a necrose da polpa) após os autotransplantes do pré-molar? David Normando

Parece estar intimamente relacionada ao estágio de formação radicular na época do transplante. Os dentes transplantados com a formação radicular incompleta ou completa demonstraram 96\% e $15 \%$ de cicatrização pulpar, respectivamente.

Argumentos: $\mathrm{O}$ fato de se evitar a contaminação bacteriana durante o procedimento cirúrgico explica a cicatrização pulpar. O forame apical com uma abertura maior que $1 \mathrm{~mm}$ facilita a revascularização do lúmen pulpar no período de 1-4 semanas após o transplante. O forame apical fechado, entretanto, em alguns casos selecionados, pode ser reaberto por meio da DAT (decomposição apical transitória), como os dentes anteriores traumatizados selecionados com o forame apical fechado.

9) Quando a cicatrização do ligamento periodontal é esperada? David Normando

A cicatrização periodontal demonstrada radio- graficamente foi incompleta e completa em 4 meses e 8 meses, respectivamente.

10) A reabsorção radicular ocorreu após o transplante? David Normando

A reabsorção radicular ocorreu após o transplante. A reabsorção radicular foi dividida em reabsorção da superfície (reparo), inflamatória, e de reposicionamento (anquilose) (Andreasen \& Hjøting, 1966). Em geral, a reabsorção radicular foi diagnosticada em 6 meses. A reabsorção radicular foi considerada significante com relação ao estágio crescente de desenvolvimento radicular e o estágio de irrupção na época do transplante. A reabsorção radicular de superfície foi detectada em $4.6 \%$, principalmente nos estágios radiculares 3, 5 e 6 (Moorrees et al., 1963). A reabsorção inflamatória foi observada em $4.8 \%$. A reabsorção de reposicionamento (anquilose) ocorreu em 4.8\%.

11) No Brasil temos diversas pessoas que apresentam perda dentária causada pela cárie dentária. A perda dentária mais comum é do primeiro molar permanente inferior. Em sua opinião, quanto tempo após a perda dentária é possível substituir um primeiro molar por um autotransplante utilizando-se os terceiros molares? David Normando

Depende de cada caso, espaço e osso. Honestamente, caso o espaço, o osso e um candidato ao autotransplante do terceiro molar realmente existam, pode haver a possibilidade, mas dependendo de cada caso.

12) Qual o melhor e o pior dente para ser transplantado? David Normando

Os melhores são os pré-molares com um canal radicular, a seguir os molares e os caninos apresentam os maiores problemas de sobrevivência. Os melhores candidatos: apenas um dente a ser substituído e dois dentes doadores (direito e esquerdo). Caso se tente em um paciente dessa forma, há duas possibilidades de "tentativa e erro". 
13) Quais são suas expectativas com relação ao uso do aparelho de Herbst em pacientes adultos entre os $\mathbf{2 0}$ e $\mathbf{3 0}$ anos de idade? Francisco Ajalmar Maia

Pessoalmente tenho tratado pacientes do gênero feminino acima dos 20-25 anos de idade com sucesso. Sugiro a leitura do artigo: Um estudo histomorfométrico e de microscopia eletrônica de varredura das alterações da cartilagem condilar humana e do tecido ósseo com relação à idade, H. U. Paulsen, J. S. Thomsen, H. P. Hougen, Li Mosekild, Clin Orthod Res, Chicago, v.2, p.6778, 1999. Conclusão: investigações qualitativas e quantitativas da atividade de "turnover" na fibrocartilagem e no tecido ósseo, descrevendo a atividade de condrócitos hipertróficos e do tecido ósseo trabecular, indicaram o potencial do crescimento condilar no grupo com faixa etária até os 30 anos de idade. A atividade do crescimento parecia declinar com a idade.

14) Como a ATM reage ao avanço contínuo da mandíbula com $\circ$ aparelho Herbst em pacientes que não estão mais em fase de crescimento? $O$ senhor segue algum protocolo para tratar esses pacientes? Omar Gabriel Silva Filho

Atualmente não tenho nenhum paciente fora da fase de crescimento para ser submetido a tratamento, todavia o crescimento condilar criado pelo Herbst constitui um crescimento da cicatrização, o mesmo sistema de crescimento de um braço fraturado. Essa fratura pode cicatrizar durante toda a vida, porém de uma forma mais lenta em indivíduos com idade avançada. Portanto, até os 30 anos o crescimento de côndilos pode ser estimulado, é o que demonstra nosso artigo sobre a microscopia e histomorfometriz eletrônica de varredura. Porém, por que a cicatrização concebida nos côndilos difere de um braço quebrado? Vale a pena tentar, caso não funcione, a osteotomia cirúrgica pode ser realizada.
15) De acordo com sua experiência no tratamento com o aparelho Herbst, qual a melhor idade para se realizar a correção da deficiência mandibular: antes, durante ou após a adolescência? Omar Gabriel Silva Filho

A melhor idade é: a qualquer momento que o paciente deseje o tratamento. Porém, a estabilidade será melhor próximo da adolescência. Normalmente tratamos quando todos os pré-molares estão irrompidos.

Cedo ou tarde. No caso do tratamento precoce: uma longa contenção com um posicionador. No caso do tratamento tardio: um período de contenção mais curto. Podemos nos basear na afirmação de nosso filósofo Soren Kierkegaard: "a vida pode ser compreendida olhando-se para trás, mas pode ser vivida olhando-se para frente". Geralmente digo aos nossos pacientes: precisamos conter aproximadamente até os 20 anos de idade. Caso você inicie cedo, terá que conter durante um longo tempo. Caso comece tarde, terá que conter por um período mais curto. A maioria dos jovens inicia o tratamento quando todos os pré-molares acabaram de irromper, mas estão cientes sobre o conceito global do tratamento com o Herbst. O tratamento abrange duas fases: 1) O aparelho Herbst. O período de tratamento será aproximadamente o mesmo para todos os grupos de indivíduos jovens. 2). A contenção interoclusal com um ativador ou um posicionador.

16) Após sua vasta experiência utilizando - aparelho Herbst para corrigir a má-oclusão Classe II, quais são suas instruções quanto ao uso desse aparelho (tempo de tratamento e contenção) em pacientes jovens e adultos? Omar Gabriel Silva Filho

O tempo de tratamento abrange de 6-8 meses. As radiografias dos côndilos da ATM (Orthopans são úteis), após 3-4 meses de tratamento, apresentarão contornos duplos na região disto-craniana indicando a nova formação óssea - o crescimento de cicatrização, isto é, estável na idade adulta. A formação óssea será de 1-2 mm cada mês e metade na fossa, 
aproximadamente o mesmo efeito em jovens e adultos, porém diferente de um indivíduo para outro, dependendo da atividade celular nos condrócitos. A contenção é realizada com um estabilizador oclusal para manter a nova inter-relação entre os dentes na maxila e na mandíbula. Um ativador, ou melhor, um posicionador, será útil e deve ser utilizado pouco mais que 12 horas, visto que a natureza repetirá o crescimento normal ocasionando um novo trespasse horizontal. O paciente deve pensar como Robin Hood que rouba dos ricos, isto é, a natureza, para manter a nova posição dentária, de onde se origina o nome posicionador dentário.

17) $O$ correto alinhamento do disco côndiloarticular mandibular é importante para a manutenção da estabilidade da correção ortodôntica, assim como para evitar a futura desordem temporomandibular (DTM). Esse alinhamento pode ser mantido com o aparelho Herbst? Se a resposta for afirmativa, como? Claudenir Rossato

É normalizado automaticamente durante o tratamento com o Herbst, caso o deslocamento do disco seja diagnosticado cedo.

\section{Claudenir Rossato}

- Doutor me Ortodontia pela Faculdade de Odontologia da Universidade de São Paulo - FOB - USP/Bauru.

- Professor adjunto do departamento de Ortodontia da Universidade Estadual de Londrina - Paraná.

\section{David Normando}

- Professor Adjunto da cadeira de Ortodontia na Universidade Federal do Pará - UFPA

- Especialista em Saúde Pública pela Universidade de Ribeirão Preto, UNAERP.

- Mestre em Odontologia pela Universidade de São Paulo, USP.

Francisco Ajalmar Maia

- Professor Adjunto Doutor do Departamento de Odontologia da UFRN.

- Mestrado e Doutorado pela FOB - USP

Diretor do Centro de Ortodontia Integrado - COI

- Natal.
18) Em adolescentes e jovens, ao se utilizar o aparelho Herbst, que tipo de alterações irreversíveis ocorrem do ponto de vista, estrutural na articulação temporomandibular (ATM)? Essas alterações são favoráveis ou desfavoráveis à correção ortodôntica e à futura estabilidade? Claudenir Rossato

A forma e a função devem ser ajustadas. Ao se alterar a função, a forma da ATM também sofrerá alterações. Sobre a questão das mudanças serem irreversíveis - em adultos: aproximadamente irreversíveis; em jovens: quantidade e direção de crescimento normais reversíveis.

19) Qual sua experiência pessoal em utilizar 0 aparelho Herbst, durante a dentadura temporária (5-6 anos)? David Normando

Não. É muito cedo. É melhor utilizá-lo mais tardiamente na puberdade do que precocemente - da mesma forma que a genética se desenvolve naturalmente, tente repetir a má oclusão normal natural, após o tratamento. Tratamento tardio - nenhuma quantidade de crescimento normal e, portanto, mais estável.

Omar Gabriel da Silva Filho

- Professor do Curso de Especialização em Ortodontia promovido pela PROFIS (Sociedade de Promoção Social do Fissurado Lábio-Palatal).

- Ortodontista do Hospital de Pesquisa e Reabilitação de Lesões Lábio-Palatais. Universidade de São Paulo, em Bauru.

Weber José da Silva Ursi

- Mestrado e Doutorado em Ortodontia na Faculdade de Odontologia de Bauru - USP.

- Professor do Curso de Especialização em Ortodontia na Faculdade de Odontologia da Universidade Estadual de São Paulo, Campus de São José dos Campos/SP. 